\title{
PHF6 Expression Levels Impact Human Hematopoietic Stem Cell Differentiation
}

OPEN ACCESS

Edited by:

Rachita Yadav

Massachusetts General Hospital,

Harvard Medical School,

United States

Reviewed by:

Andreas Reinisch,

Medizinische Universität Graz, Austria

Valerie Kouskoff,

The University of Manchester,

United Kingdom

${ }^{*}$ Correspondence:

Tom Taghon

Tom.Taghon@ugent.be

†These authors share first authorship

\#These authors share senior authorship

Specialty section:

This article was submitted to

Stem Cell Research,

a section of the journal

Frontiers in Cell and Developmental

Biology

Received: 27 August 2020

Accepted: 15 October 2020

Published: 04 November 2020

Citation:

Loontiens S, Dolens AC,

Strubbe S, Van de Walle I, Moore FE,

Depestel L, Vanhauwaert S,

Matthijssens F, Langenau DM,

Speleman F, Van Vlierberghe $P$,

Durinck K and Taghon T (2020) PHF6

Expression Levels Impact Human

Hematopoietic Stem Cell

Differentiation.

Front. Cell Dev. Biol. 8:599472.

doi: 10.3389/fcell.2020.599472

\begin{abstract}
Siebe Loontiens ${ }^{1,2 t}$, Anne-Catherine Dolens ${ }^{3+}$, Steven Strubbe ${ }^{3+}$, Inge Van de Walle, Finola E. Moore ${ }^{4}$, Lisa Depestel1,2, Suzanne Vanhauwaert ${ }^{1,2}$, Filip Matthijssens ${ }^{1,2}$, David M. Langenau ${ }^{4,5}$, Frank Speleman ${ }^{1,2}$, Pieter Van Vlierberghe ${ }^{1,2}$, Kaat Durinck ${ }^{1,2 \ddagger}$ and Tom Taghon ${ }^{3 * \neq}$
\end{abstract}

${ }^{1}$ Cancer Research Institute Ghent (CRIG), Ghent, Belgium, ${ }^{2}$ Department of Biomolecular Medicine, Ghent University, Ghent, Belgium, ${ }^{3}$ Department of Diagnostic Sciences, Ghent University, Ghent, Belgium, ${ }^{4}$ Molecular Pathology and Cancer Center, Massachusetts General Hospital, Boston, MA, United States, ${ }^{5}$ Harvard Stem Cell Institute, Cambridge, MA, United States

Transcriptional control of hematopoiesis involves complex regulatory networks and functional perturbations in one of these components often results in malignancies. Lossof-function mutations in PHF6, encoding a presumed epigenetic regulator, have been primarily described in T cell acute lymphoblastic leukemia (T-ALL) and the first insights into its function in normal hematopoiesis only recently emerged from mouse modeling experiments. Here, we investigated the role of PHF6 in human blood cell development by performing knockdown studies in cord blood and thymus-derived hematopoietic precursors to evaluate the impact on lineage differentiation in well-established in vitro models. Our findings reveal that PHF6 levels differentially impact the differentiation of human hematopoietic progenitor cells into various blood cell lineages, with prominent effects on lymphoid and erythroid differentiation. We show that loss of PHF6 results in accelerated human T cell development through reduced expression of $\mathrm{NOTCH} 1$ and its downstream target genes. This functional interaction in developing thymocytes was confirmed in vivo using a phf6-deficient zebrafish model that also displayed accelerated developmental kinetics upon reduced phf6 or notch1 activation. In summary, our work reveals that appropriate control of PHF6 expression is important for normal human hematopoiesis and provides clues towards the role of PHF6 in T-ALL development.

Keywords: hematopoiesis, PHF6, NOTCH, zebrafish, T cell development

\section{INTRODUCTION}

Hematopoietic lineage development is hierarchically organized and involves highly dynamic processes in which hematopoietic stem cells balance between self-renewal and differentiation to generate a wide variety of blood cell types. This process is tightly controlled by various key transcriptional regulators that integrate environmental cues, such as growth factors and cellintrinsic signals, including epigenetic modifications, to dictate the developmental outcome (Dege and Hagman, 2014; De Obaldia and Bhandoola, 2015; Rothenberg et al., 2016). Many of these developmental genes have been identified through the study of loss- or gain-of-function genetic alterations in hematopoietic malignancies. 
The NOTCH signaling pathway is a clear example of a molecular axis that plays a central role in both normal and malignant hematopoiesis. Constitutive NOTCH1 signaling, mainly through NOTCH1 activating mutations or mutations affecting NOTCH1 pathway regulators, are observed in over $60 \%$ of all $\mathrm{T}$ cell acute lymphoblastic leukemia (T-ALL) cases (Weng et al., 2004). Further studies subsequently also showed the crucial role of NOTCH1 signaling in normal hematopoiesis with primarily a vital role in normal $\mathrm{T}$ cell development (Radtke et al., 1999; Yashiro-Ohtani et al., 2010). NOTCH1 signaling also regulates hematopoietic stem cell (HSC) emergence (Pajcini et al., 2011; Gama-Norton et al., 2015) as well as myeloid (De Obaldia et al., 2013), erythroid (Oh et al., 2013) and lymphoid differentiation (Radtke et al., 2013), highlighting its central regulatory role in hematopoiesis. Over the last decade, multiple factors that work in crosstalk with the NOTCH1 pathway to tightly control normal $\mathrm{T}$ cell development have been described and are still a major subject of study, as exemplified by our recent work on the role of GATA3 in the process of T-lineage commitment (Van de Walle et al., 2016).

In addition to NOTCH1, PHF6 is amongst the most frequently affected genes in T-ALL due to loss-of-function mutations (Van Vlierberghe et al., 2010). PHF6, which contains 2 imperfect PHD domains, is considered to be an epigenetic reader molecule (Liu et al., 2015; Todd et al., 2015), exerting its function at least partly through its interaction with components of the NuRD complex such as CHD4 and RBBP7 (Todd and Picketts, 2012). In addition, it affects rRNA synthesis through binding UBF (Wang et al., 2013) and regulates transcription by interacting with the PAF1 transcriptional elongation complex (Zhang et al., 2013). Intriguingly, recent analyses of larger T-ALL cohorts indicate that PHF6 inactivation predominantly occurs in NOTCH1 activated T-ALLs, suggesting a functional connection between both genes. This was confirmed by the observation of accelerated leukemia development upon introducing PHF6 mutations in NOTCH1driven murine T-ALL models, partly by elevating the leukemia stem cell numbers (Hsu et al., 2019; Wendorff et al., 2019).

PHF6 mutations have not been observed thus far in nonhematopoietic malignancies, suggesting a crucial role in normal hematopoiesis. It is already shown that loss of PHF6 expression in B-ALL cells can induce a partial switch toward the $\mathrm{T}$ cell lineage (Soto-Feliciano et al., 2017) and additional recent data support a role for PHF6 in murine hematopoietic stem and progenitor cell homeostasis (McRae et al., 2019) and renewal (Miyagi et al., 2019).

In order to further scrutinize potential roles of PHF6 more broadly during normal human hematopoiesis, we studied the effects of PHF6 knockdown in normal human hematopoietic precursor cells (HPCs) and validated our observed phenotypes in a phf6 knock-out zebrafish model (Moore et al., 2012). We show dynamic regulation of PHF6 during normal human hematopoiesis and the requirement of controlled PHF6 expression to ensure normal hematopoietic lineage differentiation. Furthermore, we show that PHF6 knockdown during $\mathrm{T}$ cell development in human in vitro and in zebrafish in vivo modulates NOTCH1 expression and its downstream signaling activity, further supporting a functional interplay between both genes which we believe to be relevant for malignant transformation.

\section{MATERIALS AND METHODS}

\section{Isolation of HPCs}

Cord blood (CB), peripheral blood (PBL) and pediatric thymus samples were obtained and used according to the guidelines of the Medical Ethical Commission of Ghent University Hospital (Belgium). After lymphoprep density gradient of $\mathrm{CB}$ and PBL, mononuclear cells were isolated and used for further purifications. PBL-derived mononuclear cells were labeled with CD3-efluor780 (eBioscience), CD14-FITC (BD Biosciences), CD19-PE (Miltenyi Biotec) and CD56-APC (BD Biosciences) to sort for T cells, monocytes, B cells and NK cells, respectively. CBderived CD34 ${ }^{+}$cells were purified using magnetic activated cell sorting beads (MACS, Miltenyi Biotec). Subsequently, enriched cord blood CD34 ${ }^{+}$cells were labeled with CD34-PE (Miltenyi Biotec), CD3-APC, CD14-APC, CD19-APC and CD56-APC (APC antibodies from BD Biosciences) to sort $\mathrm{CD} 34^{+} \mathrm{Lin}^{-}$cells with a FACSAriaII (BDIS) (Waegemans et al., 2014). Thymusderived $\mathrm{CD}_{3}{ }^{+} \mathrm{T}$ cell precursors were purified using MACS as described (Van de Walle et al., 2013). Purity of the sorted cells was checked on a LSRII (BDIS) and was always > 98\%.

\section{Viral Constructs - Transduction of HPCs and Jurkat T-ALL Cells}

pLKO.1-puroR (SHC002, control shRNA) and TRCN0000020122 (SHC20122, PHF6 shRNA) lentiviral vectors were purchased from Sigma in which the puromycin resistance gene was replaced with a PCR-amplified EGFP cDNA using BamHI and KpnI restriction sites. Infectious lentivirus was produced by jetPEI (polyplus transfection ${ }^{\mathrm{TM}}$ ) mediated transfection of the 293FT cell line with either pLKO.1-SHC002EGFP or pLK0.1-SHC20122-EGFP, in conjunction of the pCMV-VSV-G (envelope) and p8.91 (packaging) constructs. The virus supernatant was harvested 2 and 3 days after transfection. Lentiviral transduction of HPCs was performed on sorted $\mathrm{CD} 34^{+} \mathrm{Lin}^{-} \mathrm{CB}$ cells or CD34 ${ }^{+}$thymocytes, previously cultured in complete IMDM medium containing 10\% FCS and supplemented with TPO $(20 \mathrm{ng} / \mathrm{ml})$, SCF $(100 \mathrm{ng} / \mathrm{ml})$ and FLT3-L $(100 \mathrm{ng} / \mathrm{ml})$ or SCF $(10 \mathrm{ng} / \mathrm{ml})$ and IL-7 $(10 \mathrm{ng} / \mathrm{ml})$, respectively, for 2 days (cord blood) or one day (thymocytes). $48 \mathrm{~h}$ after transduction, cells were harvested and sorted for $\mathrm{EGFP}^{+}$transduced cells. Jurkat T-ALL lymphoblasts were transduced with the same control or PHF6 shRNA constructs after seeding at a density of $0.5 \times 10 \mathrm{e}^{6}$ cells $/ \mathrm{ml}$ in complete RPMI medium containing 10\% FCS. Transduced Jurkat cells were harvested $96 \mathrm{~h}$ post-transduction for RNA-isolation.

\section{OP9 Cocultures and Flow Cytometry}

Transduced and sorted $\mathrm{CD}_{3} 4^{+} \mathrm{Lin}^{-} \mathrm{EGFP}^{+} \mathrm{CB}$ cells or $\mathrm{CD} 4^{+} \mathrm{EGFP}^{+}$thymocytes were seeded in a 24 well plate containing a confluent layer of either OP9 control stromal cells expressing GFP (OP9-GFP) or Delta-like-ligand1 (DLL1) 
or Delta-like-ligand4 (DLL4) expressing OP9 stromal cells (OP9-DLL1 or OP9-DLL4 respectively). All cocultures were performed in $\alpha$-MEM media (Invitrogen) supplemented with $20 \%$ heat-inactivated FCS plus $100 \mathrm{U} / \mathrm{ml}$ penicillin, $100 \mu \mathrm{g} / \mathrm{ml}$ streptomycin and $2 \mathrm{mM}$ L-glutamin (all from Invitrogen). To induce and support $\mathrm{T}$ and $\mathrm{B}$ cell differentiation, cultures were performed in the presence of SCF, IL-7 and FLT3-L (all $5 \mathrm{ng} / \mathrm{ml}$ ) on OP9-DLL1 and OP9-GFP, respectively. For the generation of NK cells, OP9-GFP cocultures were supplemented with $10 \mathrm{ng} / \mathrm{ml}$ IL-15 in addition to SCF, IL-7 and FLT3-L (all $5 \mathrm{ng} / \mathrm{ml}$ ). For myeloid differentiation, cocultures were executed with SCF, TPO, FLT3-L (all $20 \mathrm{ng} / \mathrm{ml}$ ) and G-CSF and GM-CSF (both $10 \mathrm{ng} / \mathrm{ml}$ ). For red blood cell differentiation, cultures were supplemented with SCF, EPO and TPO (50 ng/ml). For y-secretase inhibition (GSI) experiments, $1 \mu \mathrm{M}$ of $7 \mathrm{~N}$-[N-(3,5- difluorophenyl-Lalanyl)]-S-phenyl-glycine t-butyl ester (DAPT; Peptides International, Louisville, KY, United States), diluted in dimethyl sulfoxide (DMSO), was added to the co-cultures and an equal concentration of DMSO was used as control. Cocultures were performed at $37^{\circ} \mathrm{C}$ in a humidified atmosphere containing $7 \%$ (v/v) $\mathrm{CO}_{2}$ in air. Cocultures were harvested by forceful pipetting at indicated time points. Obtained cell suspensions were blocked with anti-mouse FcR $\gamma$ II/III (clone 2.4.G2) and human IgG (Fcblock, Miltenyi) to avoid non-specific binding, subsequently stained with combinations of anti-human monoclonal antibodies (BDIS, eBioscience, Biolegend and Miltenyi) and analyzed on a LSRII (BDIS).

\section{Gene Expression Profiling and Gene Set Enrichment Analysis}

RNA samples were profiled on a custom designed Agilent microarray covering all protein coding genes [33,128 mRNA probes, Human Sureprint G3 $8 \times 60 \mathrm{k}$ micro-arrays (Agilent)] and 12,000 lncRNAs (23,042 unique lncRNA probes) (Volders et al., 2013). The expression datasets generated are deposited in the Gene Expression Omnibus database (GEO) (GSE85373). See Supplementary Methods for further details.

\section{GSI Treatment in Zebrafish Embryo's and Imaging}

Tg(rag2:GFP) embryos were treated from 3 to 6 days postfertilization (dpf) with $8 \mu \mathrm{M}$ or $2 \mu \mathrm{M}$ GSI in E3 media (1X $\mathrm{E} 3+0,0001 \%$ methylene blue). DMSO was used as control treatment. The embryos were held in a 24 well plate with a maximum of 10 embryos per well and put in fresh E3 media and GSI treatment on a daily basis. Compound treatment was started 3 dpf until day 6 to avoid lethal side-effects during early embryogenesis. For the phf6 zebrafish studies, $T g$ (rag2:GFP) zebrafish were mated with either wild-type $\mathrm{AB}$ zebrafish or

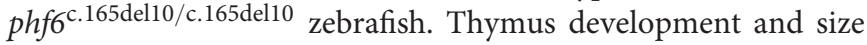
were monitored and measured from $4 \mathrm{dpf}$, when rag2 expression commences (Ma et al., 2013), until 6 dpf. The treated embryos were screened for GFP signal by the use of a Nikon SMZ18 microscope. Thymus size was measured with the NIS-Elements Analysis software. During this procedure, the zebrafish were anesthetized with $0.016 \%$ tricaine.

\section{RESULTS}

\section{PHF6 Is Dynamically Expressed During Human Hematopoiesis}

To explore the role of PHF6 in normal human hematopoietic lineage differentiation, we first measured PHF6 gene expression levels in different human blood cell types (Figure 1A). PHF6 is expressed in all hematopoietic subpopulations with prominent high expression levels in $\mathrm{CD}_{3}{ }^{+}$hematopoietic precursor cells (HPCs) and $\mathrm{CD} 19^{+} \mathrm{B}$ cells, whereas $\mathrm{CD}^{+} \mathrm{T}$ cells showed lower expression. $\mathrm{CD}^{+} 6^{+} \mathrm{NK}$ cells and particularly CD14 ${ }^{+}$monocytes displayed the lowest PHF6 expression levels, in agreement with publicly available data from Bloodspot (bloodspot.eu) (Figure 1B). Furthermore, published expression data during human lymphopoiesis (Figure 1C; Casero et al., 2015) showed a decrease in PHF6 expression in early B cell precursors compared to in $\mathrm{CD}_{3} 4^{+} \mathrm{CD} 38^{-}$HPCs but an increase during early T-lymphoid development. The latter was also observed in in vitro generated $\mathrm{T}$ cell precursors on OP9-DLL1 stromal layers, indicating that this in vitro model recapitulates PHF6 expression dynamics that occur in vivo (Figure 1D; CantéBarrett et al., 2017). Thus, PHF6 is dynamically expressed during human hematopoiesis which suggests regulatory functions during hematopoietic stem cell differentiation.

\section{Reduced PHF6 Expression Impacts on Erythroid and Lymphoid Differentiation}

To assess the impact of PHF6 loss on the differentiation potential of human HPCs, we first optimized stable PHF6 knockdown in Jurkat T-ALL cells using lentiviral gene transfer (Supplementary Figure 1a) and this confirmed strong PHF6 downregulation both at the mRNA (left) and protein level (right) which was also observed at the mRNA level in cord blood (CB)-derived CD $34^{+}$HPCs (Supplementary Figure 1b). Next, PHF6 shRNA transduced $\mathrm{CD}_{34}^{+} \mathrm{Lin}^{-} \mathrm{CB}$ HPCs were induced to differentiate in vitro in the presence of lineage-specific cytokines using wellestablished OP9 cocultures (Van de Walle et al., 2011). This revealed marked effects of reduced PHF6 levels on human hematopoiesis. In OP9-GFP cultures conditions that permit B cell development, we noticed a significant increase in both the frequency and absolute number (Figure 2A) of CD19+ ${ }^{+} \mathrm{HA}$ $\mathrm{DR}^{+} \mathrm{B}$ cells upon PHF6 knockdown compared to the control condition. In contrast, reduced $P H F 6$ expression in $\mathrm{CD}_{3} 4^{+} \mathrm{CB}$ HPCs that were cultured in NK-lineage conditions significantly decreased the generation of $\mathrm{CD}^{+} 6^{+} \mathrm{CD} 5^{-} \mathrm{NK}$ cells compared to control transduced cells, both in frequency and absolute numbers (Figure 2B). In myeloid culture conditions (Klinakis et al., 2011; Van de Walle et al., 2011), the impact of PHF6 knockdown on monocyte differentiation was modest. A slight but consistent increase in the frequency of $\mathrm{CD} 14^{+} \mathrm{CD} 4^{+}$monocytes was observed, but no significant difference was seen in absolute cell counts (Figure 2C). Given the high PHF6 expression in MEPs (Figure 1B), we also evaluated the effect of PHF6 downregulation on the differentiation of $\mathrm{CD} 34^{+} \mathrm{CB}$ HPCs toward erythrocytes and observed a significant decrease in the generation of $\mathrm{CD} 71^{+} \mathrm{CD} 45^{-}$red blood cells compared to control 

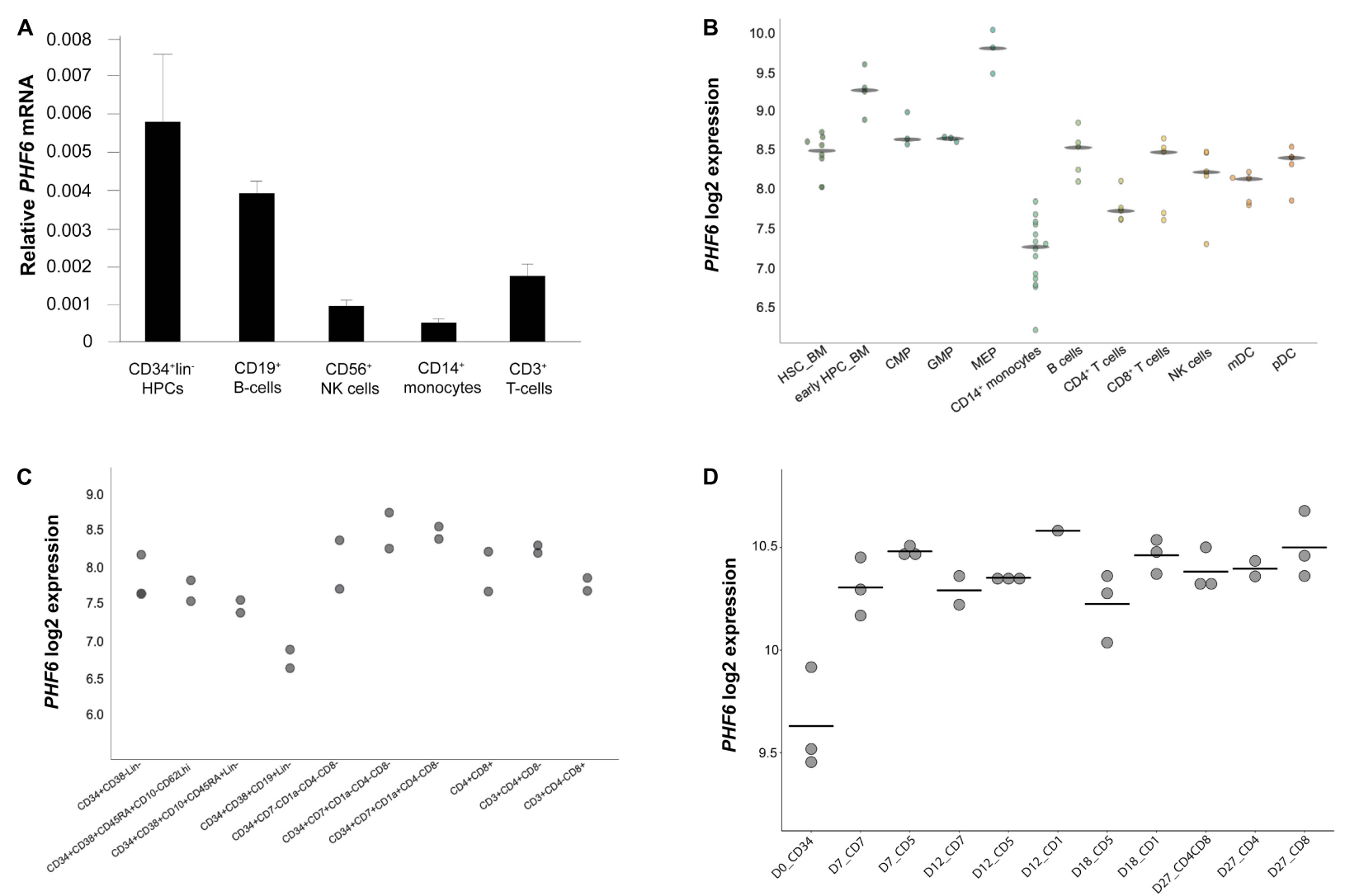

FIGURE 1 | Dynamic PHF6 expression during human hematopoiesis. Relative expression of PHF6 in various hematopoietic cell types: (A) in sorted subsets of human hematopoietic cell lineages, data shows the average of 3-4 independent samples and error bars indicate SEM; (B) adapted from Bloodspot (bloodspot.eu); (C) during human lymphopoiesis (Casero et al., 2015) or (D) during early T lymphoid development in vitro (Canté-Barrett et al., 2017).

transduced precursors (Figure 2D). On OP9-DLL1 stromal cells that permit induction of T-lineage differentiation, a small but consistent reduction in the most immature $\mathrm{CD} 34^{+} \mathrm{CD} 7^{+} \mathrm{T}$ cell precursors was observed upon PHF6 knockdown which resulted in a significant reduction in their absolute numbers compared to the control (Figure 2E).

To understand the potential underlying mechanisms of these developmental changes, we performed gene expression profiling in shPHF6 transduced $\mathrm{CD}_{3}{ }^{+}$progenitor cells that were short-term cultured on OP9-GFP and applied gene set enrichment analysis (GSEA) based on the resulting expression signatures and publically available transcriptional profiles of sorted populations of different human hematopoietic cell types (Van de Walle et al., 2013). Consistent with the preferential differentiation toward B lymphocytes of PHF6-deficient HPCs, $\mathrm{B}$ cell lineage genes (including VPREB3, RAG1 and CD200) were significantly enriched in the set of genes upregulated upon PHF6 knockdown compared to myeloid (Figure 3A) or NK cell signatures (Figure 3B). However, despite the reduction in red blood cell development, an enrichment in genes expressed higher in erythrocytes compared to HSCs was observed upon PHF6 knockdown (Figure 3C), but not for genes that are higher expressed in MEPs compared to HSCs (Figure 3D). Taken together, our data indicates that PHF6 levels modulate human lymphoid development and suggests that loss of $P H F 6$ expression results in premature induction of erythroid genes that hampers their development.

\section{PHF6 Modulates NOTCH1 Expression and Its Downstream Signaling Activity in Human T-Lineage Cells}

Given the central role of NOTCH1 during early $\mathrm{T}$ cell development and the frequent co-occurrence of activating NOTCH1 and loss-of-function PHF6 mutations in T-ALL, we evaluated the effects of PHF6 knockdown on $\mathrm{T}$ cell development in more detail. Indeed, the increase in B-lineage differentiation (Figure 2A) and reduction in early T-lymphoid development (Figure 2E) are suggestive for reduced Notch1 activity upon PHF6 knockdown. Therefore, we initiated OP9DLL1 cocultures with control or PHF6 shRNA transduced human $\mathrm{CD}_{3}{ }^{+}$thymocytes and observed remarkable accelerated differentiation toward the $\mathrm{CD} 4{ }^{+} \mathrm{CD}^{+}$double positive (DP) differentiation stage (Figure 4A). Interestingly, such enhanced DP differentiation was previously also observed in $\mathrm{CD}_{3} 4^{+}$ human thymocytes upon attenuation of NOTCH activity (Van de Walle et al., 2013, 2009), indicating that PHF6 knockdown may indeed negatively impact NOTCH1 signaling. Indeed, 
A
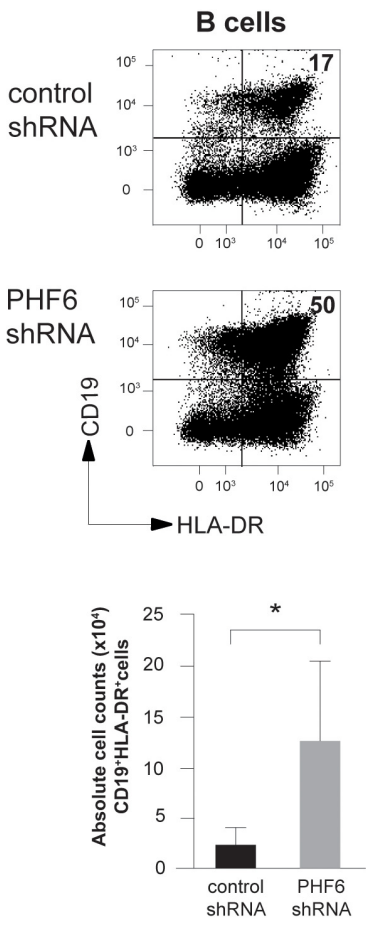

B

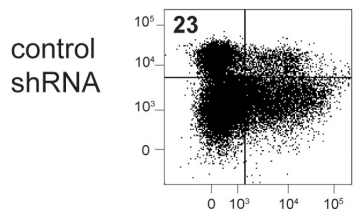

PHF6 ShRNA
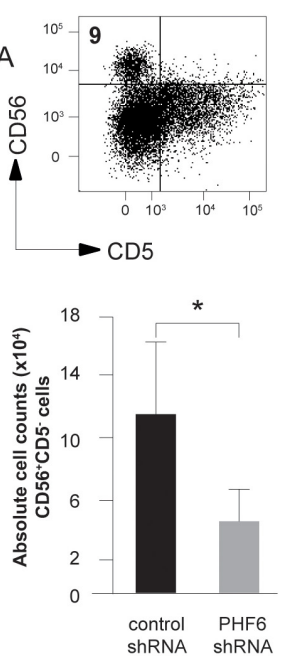

C monocytes
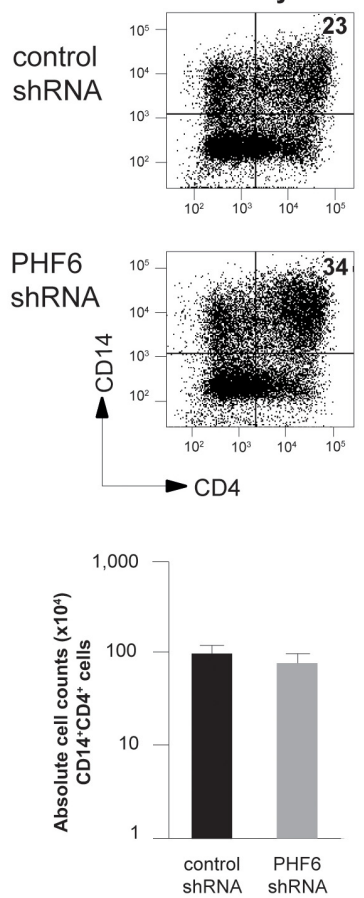

D

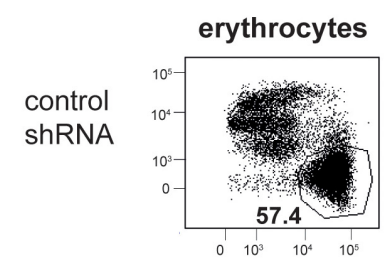
PHF6
shRNA
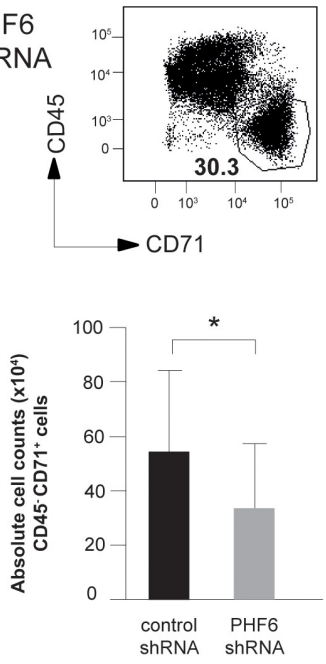

$\mathbf{E}$

control shRNA
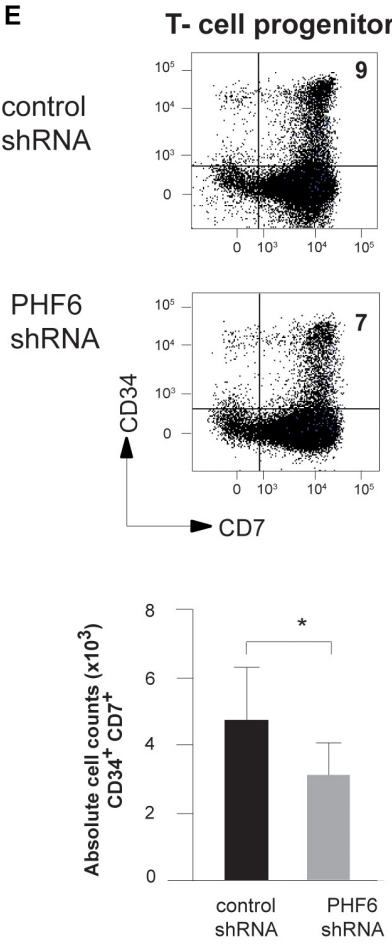

FIGURE 2 | PHF6 is essential for normal hematopoietic differentiation. (A-D) (up) Dot plots show flow cytometry analysis of control and PHF6 shRNA transduced cord blood CD34+ Lin $^{-}$precursors in OP9-GFP cocultures, showing the development of (A) CD19+HLA-DR+ B-lineage cells after 28 days of coculture,

(B) CD56 + CD5- NK cells after 21 days of coculture, (C) CD14+ CD4+ monocytes after 14 days of coculture and (D) CD45+ CD71- erythrocytes after 7 days of coculture. Bar plots (down) show absolute numbers of corresponding populations. (E) (up) Dot plots show flow cytometry analysis of control and PHF6 shRNA transduced cord blood CD34+ $\mathrm{Lin}^{-}$precursors in OP9-DLL1 cocultures, showing the development of CD34+ $\mathrm{CD} 7^{+} \mathrm{T}$ cell precursors after 7 days of coculture. Bar plot (down) shows absolute numbers of the corresponding population. Data shows average of 5-7 independent experiments and error bars indicate SEM. ${ }^{*} P<0.05$ (non-parametric paired Wilcoxon test). 


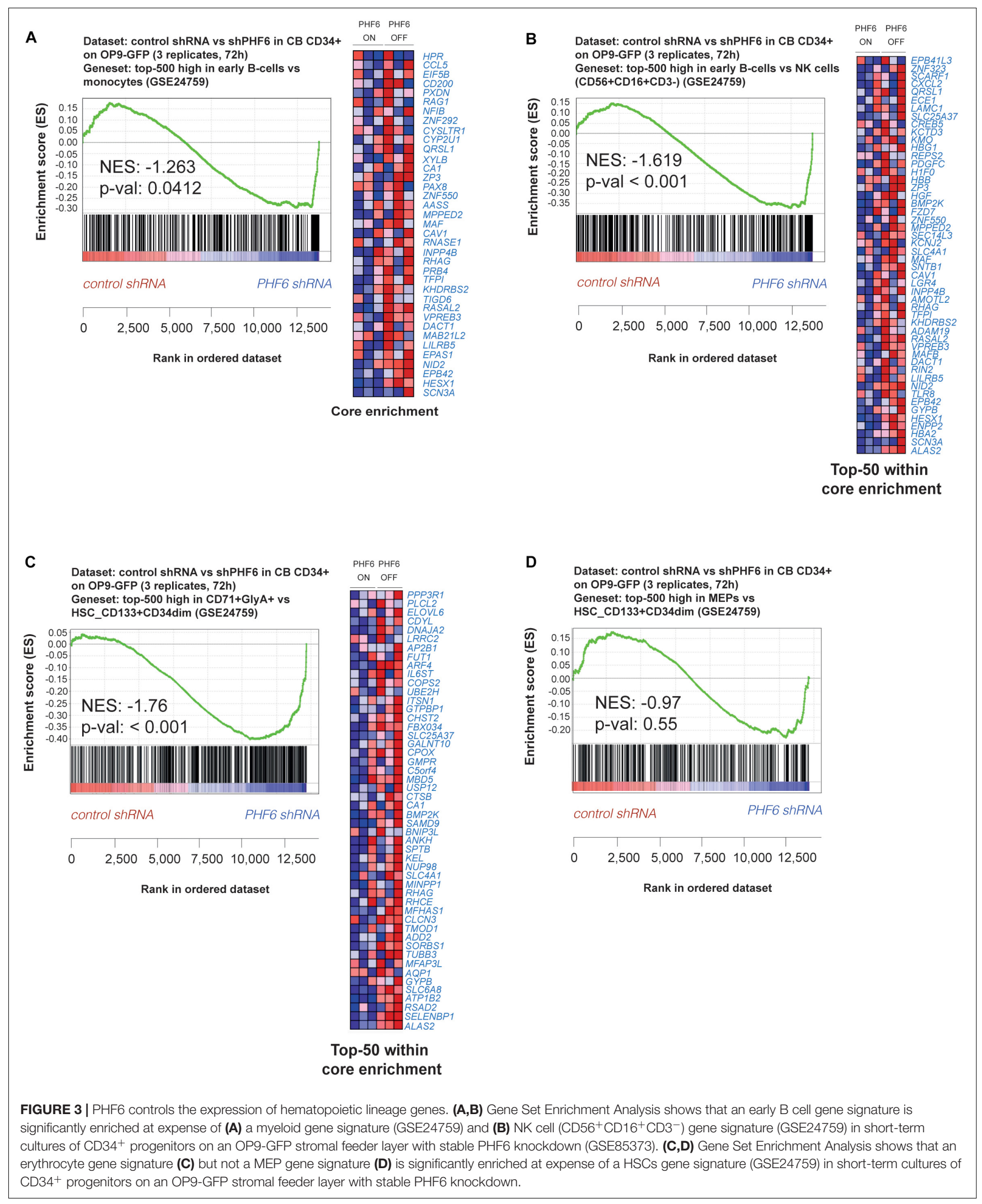




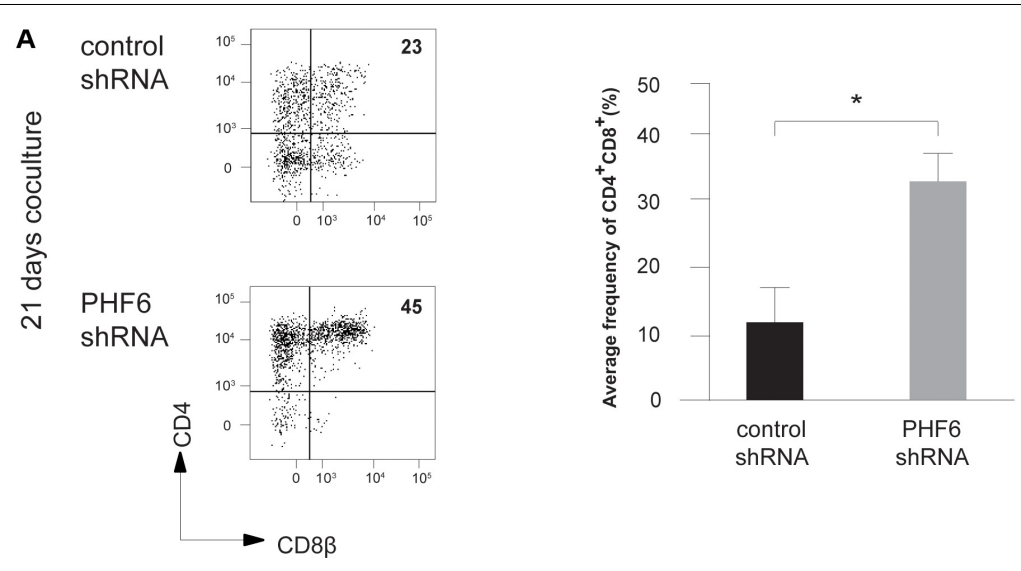

B

Jurkat

CD34+ progenitors
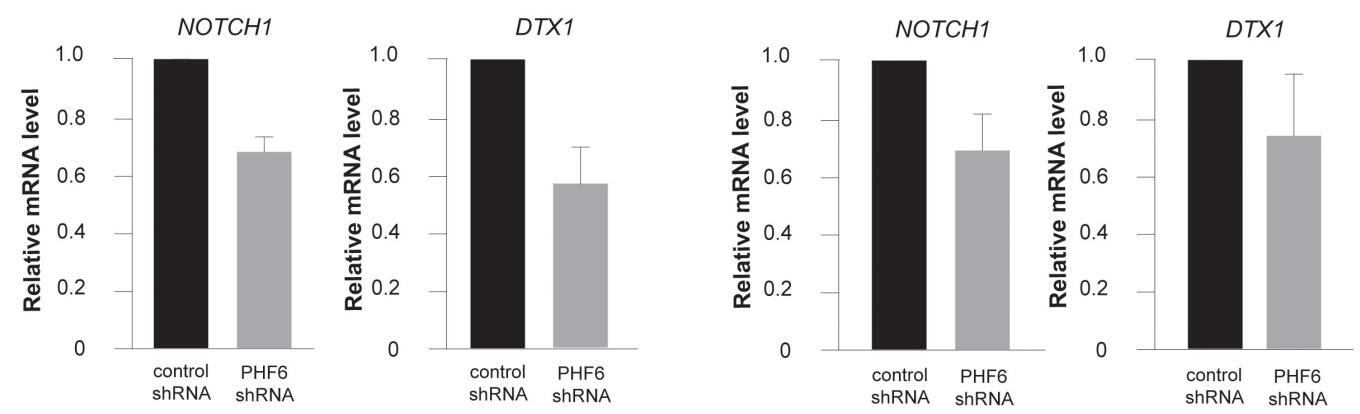

FIGURE 4 | PHF6 modulates Notch1 expression and its downstream signaling activity. (A) (left) Flow cytometry analysis of control and PHF6 shRNA transduced CD34+ thymocytes in OP9-DLL1 cocultures in the presence of IL7, SCF and FLT3L, showing the development of CD4 ${ }^{+}$CD8 $\beta^{+}$DP thymocytes after 21 days of coculture. (right) Bar plot showing the frequency of $C D 4^{+} \mathrm{CD} 8 \beta^{+} \mathrm{DP}$ thymocytes, generated in the corresponding cultures. Data shows the average of 4 independent experiments and errors bars show SEM. ${ }^{*} P<0.05$ (paired $t$-test) (B) Normalized NOTCH1 and DTX1 expression in Jurkat cells (left) and CB-derived CD34 ${ }^{+}$HPCs (right) following control or PHF6 shRNA transduction as indicated. Data shows the average expression in 3 independent samples and error bars indicate SEM.

consistent with the PHF6-mediated regulation of NOTCH1 expression in B-ALL cells (Meacham et al., 2015), we also observed reduced NOTCH1 expression upon stable PHF6 knockdown in Jurkat leukemic T cells, as well as in OP9-DLL1 cocultured human CD $34^{+}$HPCs (Figure 4B). This also affected downstream NOTCH1 signaling as shown by the concomitant reduced expression of the direct NOTCH1 target gene DTX1 (Figure 4B). In addition we found a significant enrichment of genes reported as NOTCH1-dependent in $\mathrm{CD}_{3} 4^{+} \mathrm{T}$ cell progenitors (Durinck et al., 2014) in the set of downregulated genes upon shPHF6 knockdown in Jurkat cells (Figure 5A) and in $\mathrm{CD}_{34}{ }^{+} \mathrm{T}$ cell precursors (Figure 5B). Importantly, these included canonical target genes that are NOTCH1dependent during early stages of human $\mathrm{T}$ cell development such as DTX1 and HES4 (Supplementary Table 1). These observations were confirmed independently in ALL-SILL T-ALL lymphoblasts. To this end, we transiently downregulated PHF6 by means of siRNA-mediated transfection (Supplementary Figure 2a), resulting in a downregulation of NOTCH1 and DTX1 expression (Supplementary Figures 2b,c). As shown by GSEA, also NOTCH1 downstream target genes are significantly downregulated upon PHF6 knockdown (Supplementary Figure 2d). Overall, these finding establish that loss of PHF6 not only reduces NOTCH1 expression itself, but that it also functionally affects NOTCH1 downstream signaling.

\section{PHF6 Levels Modulate NOTCH Activity During Human T Cell Development}

To further unravel the connection between PHF6 and NOTCH1 during thymopoiesis, we compared the effects of modulated PHF6 expression and altered NOTCH1 signaling activity in more detail by stable knockdown of PHF6 and pharmacological inhibition of Notch signaling using a $\gamma$-secretase inhibitor (GSI), respectively. Here, and to confirm our OP9-DLL1 derived results, we used OP9-DLL4 cocultures to provide the physiological NOTCH1 ligand. Similar as on OP9-DLL1 cocultures, thymocytes with reduced PHF6 levels progressed significantly faster toward the double positive $\left(\mathrm{CD} 4^{+} \mathrm{CD} 8^{+}\right.$, $\mathrm{DP})$ stage of $\mathrm{T}$ cell development in comparison to control transduced cells after 18 days of culture (Figure 6A). These increased numbers of DP cells are most likely to arise due 

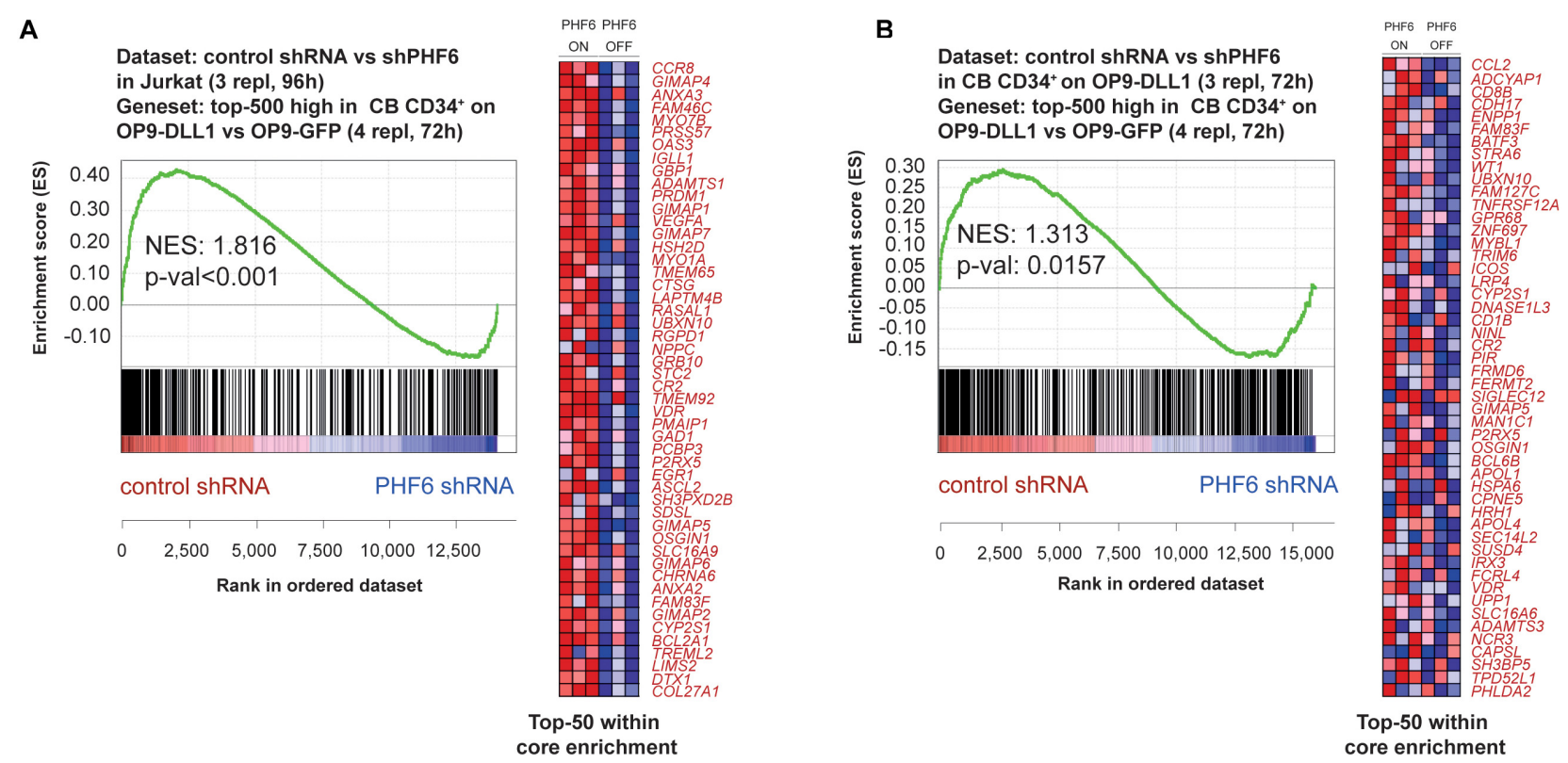

FIGURE 5 | PHF6 modulates the Notch1 gene signature. Gene Set Enrichment Analysis shows that the top-500 significantly induced genes in CB CD34+ progenitors cultured on an OP9-DLL1 stromal feeder layer in comparison to OP9-GFP cocultures are significantly enriched in the set of genes that are downregulated upon stable knockdown of PHF6 in panel (A) Jurkat T-ALL cells (GSE85373) and (B) CB CD34+ cells cultured on an OP9-DLL1 stromal feeder layer (GSE85373).

to a general accelerated differentiation, given that this rise in DP frequency and absolute counts upon PHF6 knockdown compared to controls is consistently, also already observed at earlier time points of 6 and 14 days of coculture (Supplementary Figures 3a,b). Furthermore, a comparable acceleration towards this DP stage was also observed in control transduced $\mathrm{T}$ cell precursors exposed to GSI both in frequency and absolute cell counts (Figure 6A and Supplementary Figures 3a,b), in agreement with previous findings (Van de Walle et al., 2009). Consistent with this DP phenotype and the differential requirement for NOTCH signaling activity (Van de Walle et al., 2009, 2013), loss of PHF6 skewed differentiation of human $\mathrm{T}$ cell precursors toward TCR $\alpha \beta \mathrm{T}$ cells (Figure 6B) at the expense of TCR- $\gamma \delta \mathrm{T}$ cell development (Figure 6C) both in frequencies as in absolute counts respectively, further supporting a functional parallel between NOTCH1 and PHF6 during normal $\mathrm{T}$ cell development.

\section{The Phf6-Notch Regulatory Axis During Early T Cell Development Is Conserved Between Zebrafish and Human}

Given the important differences in the role of $\mathrm{NOTCH}$ signaling during early mouse and human $\mathrm{T}$ cell development (Taghon et al., 2012), we evaluated whether zebrafish could be a more appropriate model to confirm our in vitro human PHF6 data in an in vivo context. Moreover, the transparent embryos of this model organism additionally allow to visualize developmental processes.

Sequence alignment of the Phf6 protein for human, zebrafish, mouse, chicken, chimpanzee and rat revealed a high degree of amino acid sequence conservation across these different species (Supplementary Figure 4a). Blasting (NCBI protein blast) the human PHF6 protein sequence against that of zebrafish resulted in an overall $71 \%$ peptide identity with an even higher 81.1 and $92.5 \%$ identity for both functional plant homeodomain zinc fingers 1 and 2 (PHD1 \& PHD2), thus indicating a high degree of functional conservation. In human, the highest PHF6 expression is observed in the thymus, ovary and thyroid tissues while a moderate expression is detected in spleen, testis and adipose tissue (Van Vlierberghe et al., 2010). In zebrafish, we observed phf6 expression in all dissected organs with the highest expression in ovary, testis, kidney and thymus, thus closely resembling the human expression pattern (Supplementary Figure $4 \mathbf{b}$ ). The expression of $p h f 6$ in the zebrafish kidney is particularly interesting since all hematopoietic cells types, except for thymocytes, are found in this organ (Jing and Zon, 2011; Jagannathan-Bogdan and Zon, 2013). Thus, in addition to high structural conservation, these findings also suggest functional conservation of PHF6 in zebrafish and human.

To validate such functional similarities between human and zebrafish regarding NOTCH signaling, $T g($ rag2-GFP) fish were treated with either low $(2 \mu \mathrm{M}, n=44)$ or high doses $(8 \mu \mathrm{M}$, $n=36)$ of GSI compared to the DMSO $(n=40)$ solvent control. $T g$ (rag2-GFP) zebrafish were used because this approach allows visualization of the emerging thymus through the rag2expressing $\mathrm{GFP}^{+}$thymocytes. T cell development was monitored, and thymus size measured from 4 days post fertilization (dpf) until $6 \mathrm{dpf}$. Consistent with our findings in vitro, zebrafish treated with $2 \mu \mathrm{M}$ GSI displayed accelerated T cell maturation compared to the control treated fish. At $4 \mathrm{dpf} 59 \%(2 \mu \mathrm{M})$ and $72 \%(8 \mu \mathrm{M})$ GSI-treated fish showed GFP signal in the thymus while only 

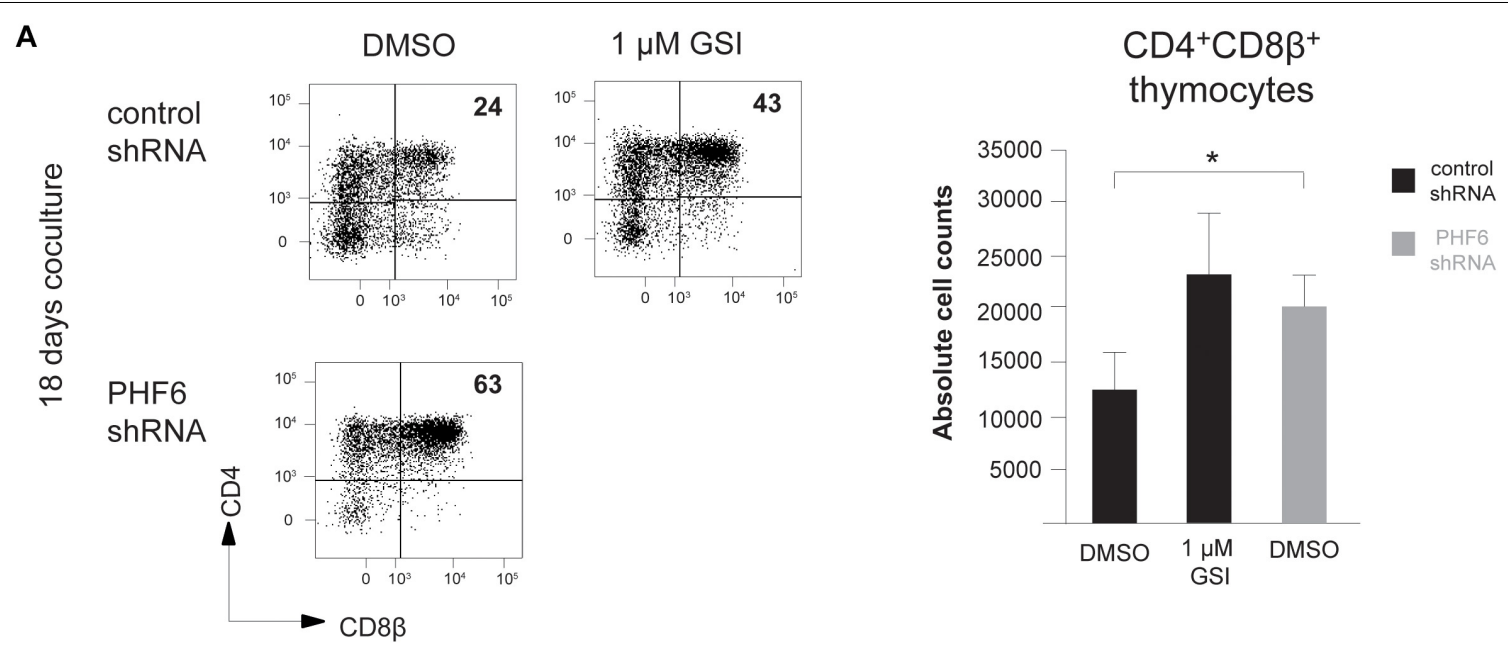

B

DMSO

$1 \mu \mathrm{M}$ GSI

$\mathrm{TCRa}^{+} \mathrm{CD}^{+}$

$\mathrm{T}$ cells
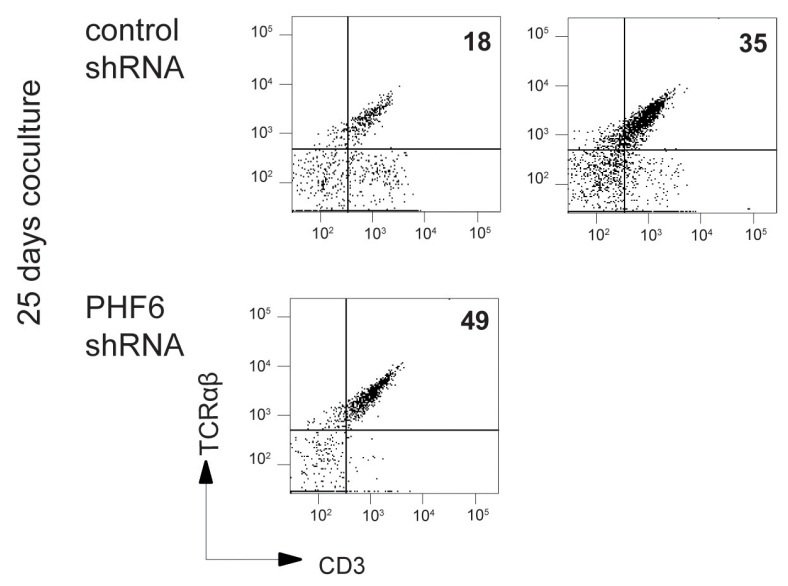

C

DMSO

$1 \mu \mathrm{M}$ GSI
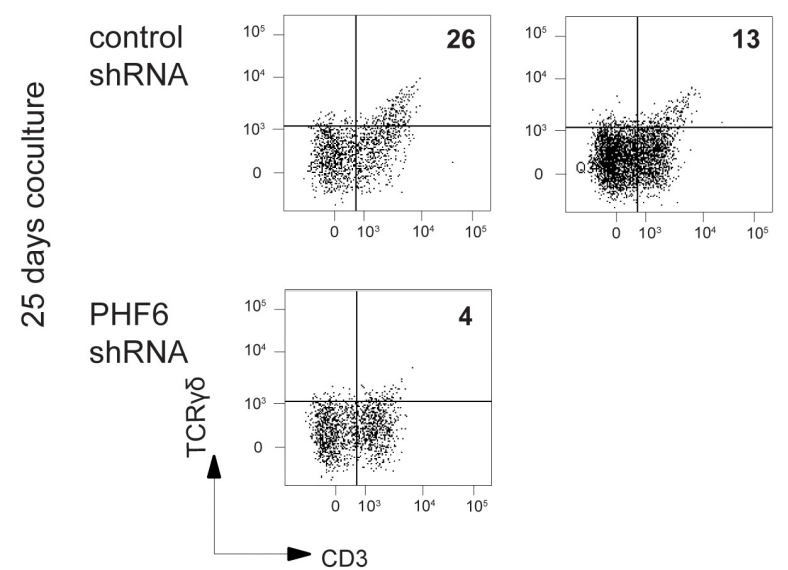

FIGURE 6 | Loss of PHF6 mimics reduced Notch activity during human T cell development. (A-C) (left) Flow cytometry analysis and (right) absolute cell counts of control versus PHF6 shRNA transduced or DMSO versus $1 \mu \mathrm{M}$ GSI treated CD34+ thymocytes in OP9-DLL1 cocultures showing (A) the development of $\mathrm{CD} 4^{+} \mathrm{CD} 8 \beta^{+}$DP thymocytes after 18 days of coculture, (B) the development of CD3 ${ }^{+} \mathrm{TCR} \alpha \beta^{+}$thymocytes after 25 days of coculture and $(\mathbf{C})$ the development of $\mathrm{CD} 3^{+} \mathrm{TCR} \gamma \delta^{+}$thymocytes after 25 days of coculture. Data shows the average of 3 independent experiments and errors bars show SEM. ${ }^{*}<0.05$ (paired $t$-test). 
$15 \%$ of the DMSO control treated fish had visible GFP expression in the thymus (Figure 7A and Supplementary Tables 2, 3). Applying a higher dose of GSI $(8 \mu \mathrm{M})$ resulted initially in faster $\mathrm{T}$ cell developmental kinetics at $4 \mathrm{dpf}$, but significantly reduced the thymus size in later stages of development at $6 \mathrm{dpf}$, consistent with our human data (Taghon et al., 2012) (Figure 6A and Supplementary Tables 2, 3). Collectively, the zebrafish data support conservation of Phf6 function and of Notch signaling during early $\mathrm{T}$ cell development between zebrafish and human.

\section{Phf6 Controls Notch1 Expression and T Cell Development in vivo}

To assess a role for Phf6 in $\mathrm{T}$ cell development in vivo, we took advantage of an available phf6 TALEN mutated zebrafish line (Moore et al., 2012; Loontiens et al., 2020). Specifically, phf6 mutations were created in exon 2 and resulted in a 10 nucleotide deletion and premature stop codon (Supplementary Figure 4c). The effect of the $10 \mathrm{bp}$ deletion in the phf6 gene was analyzed by means of RT-qPCR, and a significant downregulation of $p h f 6$ levels was seen in $p h f 6$ heterozygote fish compared to wildtype, mimicking PHF6 downregulation seen upon knockdown in vitro (Supplementary Figure 4d). We then further investigated the role of Phf6 in thymopoiesis in vivo by crossing transgenic $\operatorname{Tg}(\operatorname{rag} 2: G F P)$ zebrafish with either $\mathrm{AB}$ wildtype or $p h f \sigma^{\mathrm{c} .165 \mathrm{del} 10 / \mathrm{c} .165 \mathrm{del} 10}$ mutant zebrafish. The resulting offspring were kept separately at $4 \mathrm{dpf}$ and thymus development was monitored until $6 \mathrm{dpf}$ (Figures 7B,C). At $4 \mathrm{dpf}$, significantly more phf6 ${ }^{\mathrm{c} .165 \mathrm{del} 10 /+}$ mutant fish showed GFP expression in the thymus region compared to the $\mathrm{AB}$ wild type (62 versus 14\%, respectively, Figures 7B,C and Supplementary Table 4). By 5 dpf, almost all (96\%) of the phf6.165del10/+ mutant fish displayed detectable rag2-GFP expression while the wild type fish needed 6 days to reach such frequencies (Figures 7B,C and Supplementary Table 4). Independent morpholino experiments confirmed these Phf6-mediated effects on T cell development (Supplementary Figure 4e). Quantification of thymus size revealed a significant larger thymus at 4 and $5 \mathrm{dpf}$ for phf6 $6^{\text {c.165del10/+ }}$ mutant compared to wildtype fish (Figure 7B and Supplementary Table 4), indicating that phf6 downregulation results in initial faster kinetics of $\mathrm{T}$ cell development. In agreement, RT-qPCR analysis of sorted thymocytes (Loontiens et al., 2019) showed a downregulation of notch1a expression in phf6 $6^{\text {c.165del10/+ }}$ embryos compared to thymocytes from wild type embryo's (Figure 7D), as well as in thymocytes of adult $p h f 6^{\text {c.165del10/+ }}$ versus wild type zebrafish (Figure 7D). Collectively, these in vivo findings confirm that Phf6 modulates Notch1 expression during thymopoiesis and that loss of Phf6 mimics the effects of reduced Notch1 expression on thymopoiesis in zebrafish, similarly as observed in human.

\section{DISCUSSION}

Despite the fact that loss-of-function PHF6 mutations are amongst the most frequent genetic alterations in T-ALL, the role of PHF6 in normal and malignant hematopoiesis is functionally still uncharacterized. Here, we show that PHF6 is dynamically expressed during hematopoiesis and that PHF6 levels functionally impact normal human hematopoietic lineage differentiation. Consistent with the strong association between loss-of-function PHF6 mutations and activating NOTCH1 mutations in T-ALL (Wang et al., 2011; Li et al., 2016), we reveal that NOTCH1 expression and signaling is dependent on PHF6 expression during normal $\mathrm{T}$ cell development. We observed similar developmental effects for both PHF6 and Notch activity in our in vitro PHF6 loss-of-function experiments for human $\mathrm{T}$ cell development. In addition, we independently confirmed these findings in vivo using a pfh6 knock-out zebrafish model.

Importantly, the findings from this manuscript are consistent with our previous work on the role of Notch signaling during human $\mathrm{T}$ cell development. The differentiation of human $\mathrm{CD}_{3} 4^{+}$thymocytes into DP and TCR $\alpha \beta$-lineage thymocytes is indeed dependent on a reduction of Notch signaling activity in the OP9-DLL1 (or OP9-DLL4) coculture system that can be triggered by adding low dosages of GSI (Taghon et al., 2012). In vivo, this reduction in Notch activation is equally important (Durinck et al., 2014), as also illustrated by the induction of T-ALL upon continuous Notch activation (Ferrando, 2009), and this could be controlled through migration within the thymic microenvironment to regions with a reduced availability of Notch ligands (Van de Walle et al., 2013). Also the reduction in TCR $\gamma \delta \mathrm{T}$ cell development that occurs upon knockdown of PHF6 corresponds with the strong Notch requirement for their development (Van de Walle et al., 2009, 2013). We recently illustrated that Notch activity during early human $\mathrm{T}$ cell development is also dependent on GATA3 activity that mediates downregulation of DTX1 (Van de Walle et al., 2016), consistent with the impact of reduced PHF6 expression on NOTCH1 and DTX1 expression. Intriguingly, besides a direct connection between PHF6 and NOTCH1 as shown by the binding of PHF6 to the transcription start site locus of NOTCH1 in Jurkat cells (Meacham et al., 2015), recent data have shown that loss of PHF6 function also increases chromatin accessibility at the GATA3 locus (Soto-Feliciano et al., 2017), suggesting that the observed effects of PHF6 knockdown on T cell development may be mediated by several transcriptional mediators in addition to changes in NOTCH1.

While it remains to be determined if PHF6 has a similar role in mice, we choose not to use this organism for in vivo experiments given the significant differences between mouse and human regarding the Notch signaling requirements during $\mathrm{T}$ cell development (Taghon et al., 2012). Indeed, while Notch signaling is important in both mouse and human to induce T-cell lineage specification in multipotent hematopoietic precursors (Wilson et al., 2001; Van de Walle et al., 2009), the subsequent stages of $\mathrm{T}$ cell development show altered Notch signaling requirements in both species. While differentiation of specified $\mathrm{T}$ cell precursors into DP TCR- $\alpha \beta$ lineage cells is highly Notch-dependent in mice (Ciofani et al., 2006; Taghon et al., 2006), this developmental process occurs much more efficient in human when Notch signaling is reduced (Van de Walle et al., 2009, 2013; Dolens et al., 2020). In contrast, TCR $\gamma \delta$ $\mathrm{T}$ cell development is highly Notch-dependent in human 
A

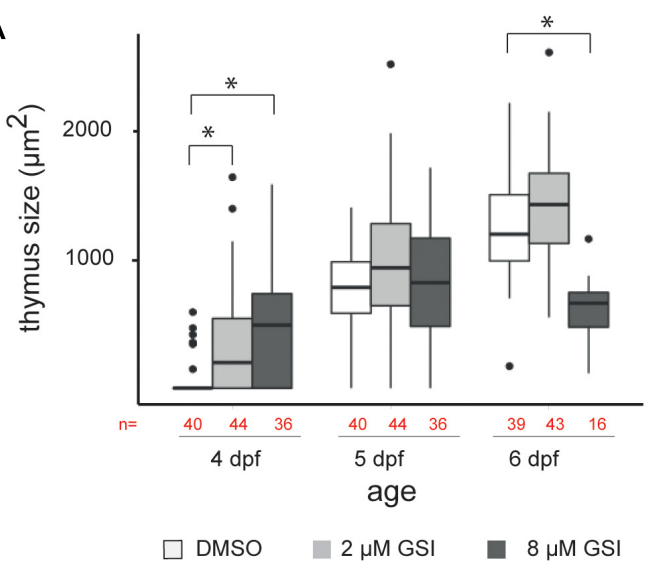

C

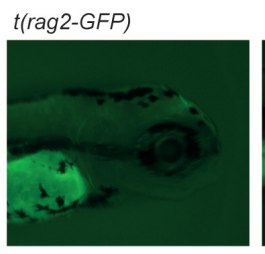

t(rag2-GFP); phf6 ${ }^{\text {c.165de/10/+ }}$

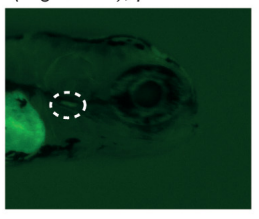

$5 d p f$
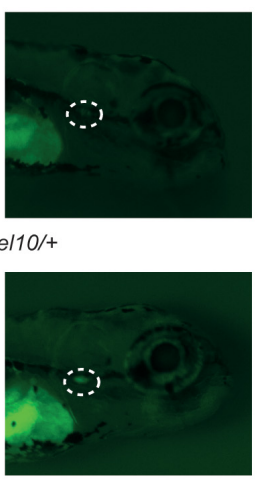
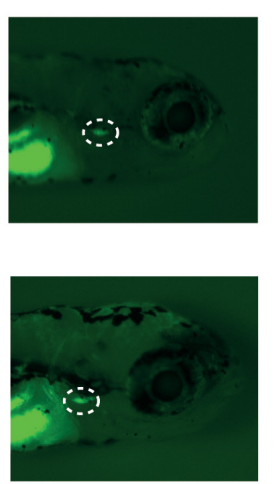

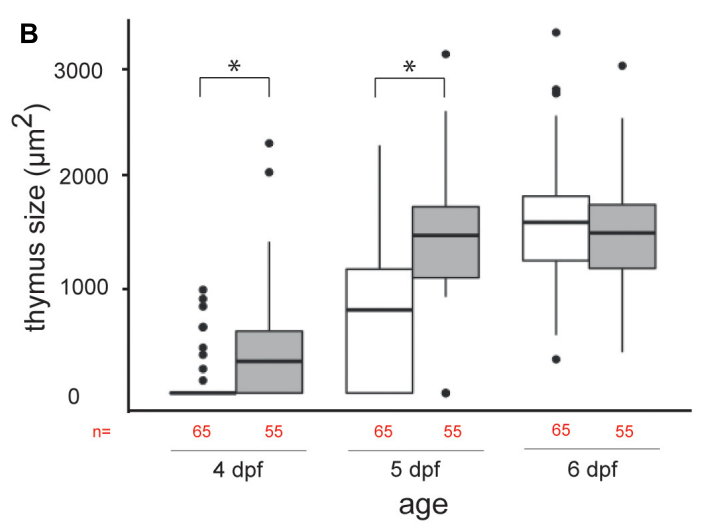

$\square$ wild type $\quad \square$ phf6 $^{\mathrm{c} .165 d e l 10 /+}$

D

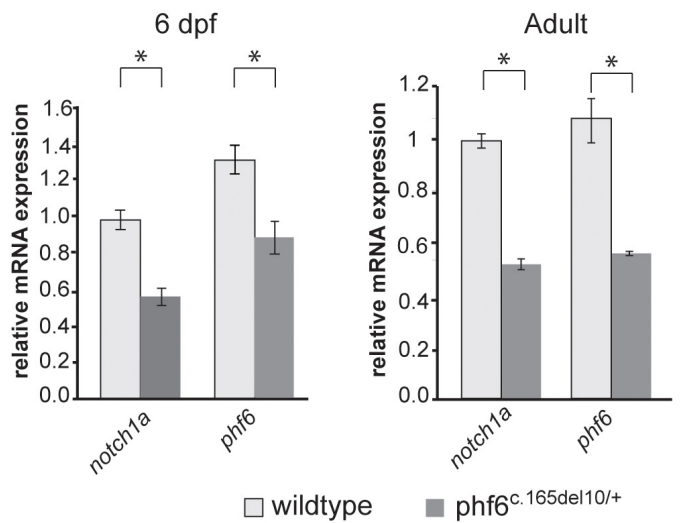

FIGURE 7 | phf6 downregulation accelerates T cell development in vivo. (A) Box plot showing thymus size $\left(\mu \mathrm{m}^{2}\right.$ ) at 4, 5, and 6 days post-fertilization (dpf) based on GFP signal of wild type (AB) fish treated with 2 or $8 \mu \mathrm{M}$ of gamma-secretase inhibitor (GSI) or DSMO as control treatment. Details on these results are provided in Supplementary Table 2 and statistical analysis is shown in Supplementary Table $\mathbf{3},{ }^{*} P<0.05$ (Wilcoxon rank sum test). (B) Boxplot showing thymus size ( $\mu \mathrm{m}^{2}$ ) of wild type (AB) and phf6 ${ }^{c .165 d e l 10 /+}$ heterozygous embryos from 4 until 6 dpf based on rag2-GFP signal quantification. ${ }^{*} P<0.05$ (Wilcoxon rank sum test,

Supplementary Table 4). (C) Representative image of thymus visualization used for quantification of data as shown in panel (A). Original magnification X30. Circle with white dashed line indicates emerging thymus. (D) Average normalized notch1a and phf6 expression in sorted T cells of 4 replicates of 100 pooled wild type (AB) and phf6. $165 \mathrm{del10/+}$ embryo's on $6 \mathrm{dp}$ (left) and of 3 replicates of 6 pooled wildtype and 6 pooled phf6 ${ }^{\mathrm{c} .165 \mathrm{del} 10 /+}$ adult zebrafish (right). Error bars indicate SEM, ${ }^{*} P<0.05$ (unpaired $T$-test).

(Van de Walle et al., 2009, 2013; Dolens et al., 2020) but less in mouse (Ciofani et al., 2006; Taghon et al., 2006). In addition, genetic studies in zebrafish are increasingly used to study human genetic aberrations, as illustrated for BCL11B mutations during T cell development (Punwani et al., 2016). The findings in this manuscript further support the importance of zebrafish as a model to study normal hematopoiesis and particularly $\mathrm{T}$ cell development (Zhang and Wiest, 2016) as both the effects of PHF6 knockdown and of reduced NOTCH signaling activation on human $\mathrm{T}$ cell development were confirmed in vivo. The possibility to image $\mathrm{T}$ cell development in embryos also allows to perform kinetic studies in vivo, which is also a significant strength of in vitro studies, since they allow to reveal developmental abnormalities that may be obscured in adult organisms as a result of homeostatic expansion mechanisms. However, in zebrafish, thymopoiesis consists out of two waves, with the first wave starting from $3 \mathrm{dpf}$ and mainly producing $\alpha \beta$-CD4 T cells, while the second wave commences at $8 \mathrm{dpf}$ and gives rise to $\alpha \beta$ CD4, $\alpha \beta-C D 8$ and $\gamma \delta \mathrm{T}$ cells (Tian et al., 2017). This study suggests that both Phf6 and Notch influence this first wave of thymopoiesis, producing the $\alpha \beta-C D 4$ T cells. The enhanced TCR$\alpha \beta$ differentiation at the expense of the $\gamma \delta$-lineage could not be assessed by our experimental timeframe and set up. Additional studies are required to fully explore to what extent hematopoiesis is conserved between human and zebrafish as compared to mice (Mestas and Hughes, 2004; Payne and Crooks, 2007). 
The observed effect of PHF6 knockdown on B cell development is also in line with reduced NOTCH1 signaling activity since B-lineage differentiation is extremely sensitive to small dosages of signaling activity. Although these experiments were performed on OP9-GFP stromal cells in the absence of a NOTCH ligand that is sufficiently strong to induce $\mathrm{T}$ cell development and to fully inhibit B cell development, OP9 cells express significant levels of Jagged-1 and -2 (Schmitt and ZúñigaPflücker, 2002) that can partially hamper B cell development (Van de Walle et al., 2011). However, given the significant increase in B cell signature genes upon PHF6 knockdown, it is possible that PHF6 directly regulates at least some of these genes independent of Notch signaling activity, consistent with its role as an epigenetic regulator (Soto-Feliciano et al., 2017). Such a direct regulatory role for PHF6 may also be required for the expression of NK-lineage genes that are not Notch-dependent in all circumstances, such as DTX1 and TBX21 (Rankin et al., 2013), although we have also demonstrated that Notch signaling enhances NK cell development (De Smedt et al., 2007). While we mainly focused on lymphocyte development, the lack of effect on monocytic differentiation upon PHF6 knockdown and the low expression that is observed in ex vivo isolated monocytes suggests that PHF6 is mainly involved in regulating lymphocyte development. Nevertheless, we also observed a clear phenotype with respect to erythroid development. Although the impact of reduced PHF6 expression was apparently inconsistent with respect to the reduced development of erythrocytes compared to the increased expression of red blood cell genes, the premature expression of these genes in HPCs may hamper the appropriate differentiation of these precursors toward erythrocytes given that genes from the intermediate MEP stage were not altered upon PHF6 knockdown. Intriguingly, also Notch activation has been implicated in erythroid development in mice (Oh et al., 2013).

In the context of leukemia, PHF6 has been suggested to act as an oncogene in B-ALL (Meacham et al., 2015; SotoFeliciano et al., 2017). Although the enhanced differentiation of $\mathrm{CD}_{34}{ }^{+}$HPCs towards the B cell lineage upon PHF6 knockdown might seem inconsistent with such an oncogenic role, it is well-established that context-specific roles may alter protein function and/or requirement. This has for instance been clearly illustrated for Notch activation that strongly antagonizes early B cell development (Wilson et al., 2001), yet, Notch2 activation is later essential within the B cell lineage for marginal zone B cell development (Saito et al., 2003). Moreover, activating Notch mutations have been described in B cell malignancies (Chiang et al., 2016). In T-ALL, PHF6 and NOTCH1 are considered to act as tumor suppressor and oncogenes, respectively (Ferrando, 2009; Van Vlierberghe et al., 2010). Therefore, our finding that PHF6 knockdown attenuates NOTCH1 activity may seem counterintuitive in the context of T-ALL oncogenesis. However, in T-ALL patients that harbor lossof-function PHF6 mutations, there is a significant association with activating mutations in NOTCH1 or its downstream target IL7R (Wang et al., 2011; Vicente et al., 2015; Li et al., 2016), indicating that reduced PHF6 function triggers the cells to compensate for the reduced activity of these critical T-lineage proliferation/survival pathways.
In conclusion, our results reveal an important regulatory role for PHF6 during normal hematopoiesis and provide novel clues towards the tumor suppressor role of PHF6 in T-ALL.

\section{DATA AVAILABILITY STATEMENT}

The datasets presented in this study can be found in online repositories. The names of the repository/repositories and accession number(s) can be found below: https://www.ncbi.nlm. nih.gov/geo/, GSE85373.

\section{ETHICS STATEMENT}

The studies involving human participants were reviewed and approved by the Medical Ethical Commission of Ghent University Hospital (Belgium). Written informed consent to participate in this study was provided by the participants' legal guardian/next of kin. The animal study was reviewed and approved by Massachusetts General Hospital Subcommittee on Research Animal Care (OLAW Assurance \# A3596-01 under protocol \#2011N000127) and by the Ghent University Committee on Ethics of Animal Experiments (Ghent University Hospital, Ghent, Belgium; Permit Number: ECD 11/37).

\section{AUTHOR CONTRIBUTIONS}

$\mathrm{KD}$, SL, AC-D, SS, and IV performed the experiments, analyzed the data, and wrote the manuscript. FEM performed the experiments and analyzed the data. SV, LD, and FM performed the experiments. DL provided reagents and intellectual guidance. PV, FS, and TT designed the research, analyzed the data, and wrote the manuscript. All authors contributed to the article and approved the submitted version.

\section{FUNDING}

This work was supported by the Odysseus program (to PV and TT) of the Fund for Scientific Research Flanders (FWO Vlaanderen) and grants from the FWO ("FWO Vlaanderen" research projects G.0202.09, G.0869.10N, 3G055013N, 3G056413N, G037918N to FS; 3GA00113N, 3G065614, G.0C47.13N to PV and G0B2913N, G037514N, 3G002711 to TT; doctoral grant to SL; postdoctoral grants to IV and SV), the Concerted Research Action of Ghent University (GOA, BOF18-GOA-024 to TT and PV, $01 G 01910$ to FS) and the Interuniversity Attraction Poles Program from the Belgian Science Policy (IUAP P7/03 to FS and P7/39 to TT), BOF (postdoctoral grant to KD), Stichting tegen Kanker (to FS and TT), Villa Joep (to FS), Kom op tegen Kanker (to KD, FM, SL, and SV). IWT Vlaanderen (Ph.D. grant to KD and A-CD). This work was also supported by Alex's Lemonade Stand Foundation (DL), The Live Like Bella Foundation for Childhood Cancer (DL), American Cancer Society (DL), the NIH (R01CA211734-01A1, 
DL) and the Massachusetts General Hospital (MGH) Howard Goodman Fellowship (DL). FEM was supported by NIH grant 5F32DK098875. Flow cytometry and sorting services were supported by MGH Pathology CNY Flow Cytometry Core shared instrumentation grant 1S10RR023440-01A.

\section{ACKNOWLEDGMENTS}

We thank S. Vermaut, A. Eggermont, and G. Dewyn for excellent technical assistance, J.-C. Zuniga-Pflucker (University

\section{REFERENCES}

Canté-Barrett, K., Mendes, R. D., Li, Y., Vroegindeweij, E., Pike-Overzet, K., Wabeke, T., et al. (2017). Loss of CD44dim expression from early progenitor cells marks T-cell lineage commitment in the human thymus. Front. Immunol. 8:32. doi: 10.3389/fimmu.2017.00032

Casero, D., Sandoval, S., Seet, C. S., Scholes, J., Zhu, Y., Ha, V. L., et al. (2015). Long non-coding RNA profiling of human lymphoid progenitor cells reveals transcriptional divergence of B Cell and t cell lineages. Nat. Immunol. 16, 1282-1291. doi: 10.1038/ni.3299

Chiang, M. Y., Radojcic, V., and Maillard, I. (2016). Oncogenic notch signaling in T-Cell and B-Cell lymphoproliferative disorders. Curr. Opin. Hematol. 23, 362-370. doi: 10.1097/MOH.0000000000000254

Ciofani, M., Knowles, G. C., Wiest, D. L., von Boehmer, H., and Zúñiga-Pflücker, J. C. (2006). Stage-Specific and differential notch dependency at the $A \beta$ and $\Gamma \delta T$ lineage bifurcation. Immunity 25, 105-116. doi: 10.1016/j.immuni.2006.05.010

De Obaldia, M. E., Bell, J. J., Wang, X., Harly, C., Yashiro-Ohtani, Y., DeLong, J. H., et al. (2013). T Cell Development requires constraint of the myeloid regulator C/EBP- $\alpha$ by the notch target and transcriptional repressor Hes1. Nat. Immunol. 14, 1277-1284. doi: 10.1038/ni.2760

De Obaldia, M. E., and Bhandoola, A. (2015). Transcriptional regulation of innate and adaptive lymphocyte lineages. Annu. Rev. Immunol. 33, 607-642. doi: 10. 1146/annurev-immunol-032414-112032

De Smedt, M., Taghon, T., Van de Walle, I., De Smet, G., Leclercq, G., and Plum, J. (2007). Notch signaling induces Cytoplasmic CD3 epsilon expression in human differentiating NK cells. Blood 110, 2696-2703. doi: 10.1182/blood-2007-03082206

Dege, C., and Hagman, J. (2014). Mi-2/NuRD chromatin remodeling complexes regulate B and T-lymphocyte development and function. Immunol. Rev. 261, 126-140. doi: 10.1111/imr.12209

Dolens, A. C., Durinck, K., Lavaert, M., Van der Meulen, J., Velghe, I., De Medts, J., et al. (2020). Distinct Notch1 and BCL11B requirements mediate human $\Gamma \delta / \mathrm{A} \beta$ T cell development. EMBO Rep. 21:6. doi: 10.15252/embr.201949006

Durinck, K., Wallaert, A., Van de Walle, I., Van Loocke, W., Volders, P. J., Vanhauwaert, S., et al. (2014). The notch driven long non-coding RNA repertoire in T-Cell acute lymphoblastic leukemia. Haematologica 99, 18081816. doi: $10.3324 /$ haematol.2014.115683

Ferrando, A. A. (2009). The role of NOTCH1 signaling in T-ALL. Hematol. Educ. Prog. Am. Soc. Hematol. 2009, 353-361. doi: 10.1182/asheducation-2009.1.353

Gama-Norton, L., Ferrando, E., Ruiz-Herguido, C., Liu, Z., Guiu, J., Islam, A. B., et al. (2015). Notch signal strength controls cell fate in the Haemogenic endothelium. Nat. Commun. 6:8510. doi: 10.1038/ncomms9510

Hsu, Y. C., Chen, T. C., Lin, C. C., Yuan, C. T., Hsu, C. L., Hou, H. A., et al. (2019). Phf6-Null hematopoietic stem cells have enhanced self-renewal capacity and Oncogenic potentials. Blood Adv. 3, 2355-2367. doi: 10.1182/bloodadvances. 2019000391

Jagannathan-Bogdan, M., and Zon, L. I. (2013). Hematopoiesis. Development 140, 2463-2467. doi: 10.1242/dev.083147

Jing, L., and Zon, L. I. (2011). Zebrafish as a model for normal and malignant Hematopoiesis. Dis. Models Mech. 4, 433-438. doi: 10.1242/dmm.006791

Klinakis, A., Lobry, C., Abdel-Wahab, O., Oh, P., Haeno, H., Buonamici, S., et al. (2011). A novel tumour-suppressor function for the notch pathway in myeloid Leukaemia. Nature 473, 230-233. doi: 10.1038/nature09999 of Toronto) for OP9 stromal cells, K. Francois and G. Van Nooten (Department of Cardiac Surgery, Ghent University Hospital) for thymus tissue, the Red Cross Flanders for cord blood and the Ghent University Hospital Hematopoietic Biobank.

\section{SUPPLEMENTARY MATERIAL}

The Supplementary Material for this article can be found online at: https://www.frontiersin.org/articles/10.3389/fcell.2020. 599472/full\#supplementary-material

Li, M., Xiao, L., Xu, J., Zhang, R., Guo, J., Olson, J., et al. (2016). Co-existence of PHF6 and NOTCH1 mutations in adult T-Cell acute lymphoblastic leukemia. Oncol. Lett. 12, 16-22. doi: 10.3892/ol.2016.4581

Liu, Z., Li, F., Zhang, B., Li, S., Wu, J., and Shi, Y. (2015). Structural basis of plant Homeodomain finger 6 (PHF6) recognition by the retinoblastoma binding protein 4 (RBBP4) component of the nucleosome remodeling and deacetylase (NuRD) complex. J. Biol. Chem. 290, 6630-6638. doi: 10.1074/jbc.M114.610196

Loontiens, S., Depestel, L., Vanhauwaert, S., Dewyn, G., Gistelinck, C., Verboom, K., et al. (2019). Purification of high-quality RNA from a small number of fluorescence activated cell sorted zebrafish cells for RNA sequencing purposes. BMC Genom. 20:228. doi: 10.1186/s12864-019-5608-2

Loontiens, S., Vanhauwaert, S., Depestel, L., Dewyn, G., Van Loocke, W., Moore, F. E., et al. (2020). A Novel TLX1-driven T-ALL zebrafish model: comparative genomic analysis with other leukemia models. Leukemia doi: 10.1038/s41375020-0938-2. [Epub ahead of print].

Ma, D., Wei, Y., and Liu, F. (2013). Regulatory mechanisms of thymus and T cell development. Dev. Compar. Immunol. 39, 91-102. doi: 10.1016/j.dci.2011.12. 013

McRae, H. M., Garnham, A. L., Hu, Y., Witkowski, M. T., Corbett, M. A., Dixon, M. P., et al. (2019). PHF6 regulates hematopoietic stem and progenitor cells and its loss synergizes with expression of TLX3 to cause leukemia. Blood 133, 1729-1741. doi: 10.1182/blood-2018-07-860726

Meacham, C. E., Lawton, L. N., Soto-Feliciano, Y. M., Pritchard, J. R., Joughin, B. A., Ehrenberger, T., et al. (2015). A genome-scale in vivo loss-of-function screen identifies Phf6 as a lineage-specific regulator of leukemia cell growth. Genes Dev. 29, 483-488. doi: 10.1101/gad.254151.114

Mestas, J., and Hughes, C. C. W. (2004). Of mice and not men: differences between mouse and human immunology. J. Immunol. 172, 2731-2738. doi: 10.4049/ jimmunol.172.5.2731

Miyagi, S., Sroczynska, P., Kato, Y., Nakajima-Takagi, Y., Oshima, M., Rizq, O., et al. (2019). The Chromatin-binding protein Phf6 restricts the selfrenewal of Hematopoietic stem cells. Blood 133, 2495-2506. doi: 10.1182/blood. 2019000468

Moore, F. E., Reyon, D., Sander, J. D., Martinez, S. A., Blackburn, J. S., Khayter, C., et al. (2012). Improved somatic mutagenesis in zebrafish using transcription activator-like effector nucleases (TALENs). PLoS One 7:e37877. doi: 10.1371/ journal.pone.0037877

Oh, P., Lobry, C., Gao, J., Tikhonova, A., Loizou, E., Manet, J., et al. (2013). In vivo mapping of notch pathway activity in normal and stress hematopoiesis. Cell Stem Cell 13, 190-204. doi: 10.1016/j.stem.2013.05.015

Pajcini, K. V., Speck, N. A., and Pear, W. S. (2011). Notch signaling in mammalian hematopoietic stem cells. Leukemia 25, 1525-1532. doi: 10.1038/leu.2011.127

Payne, K. J., and Crooks, G. M. (2007). Immune-cell lineage commitment: translation from mice to humans. Immun. Cell Press 26, 674-677. doi: 10.1016/ j.immuni.2007.05.011

Punwani, D., Zhang, Y., Yu, J., Cowan, M. J., Rana, S., Kwan, A., et al. (2016). Multisystem anomalies in severe combined immunodeficiency with mutant BCL11B. New Engl. J. Med. 375, 2165-2176. doi: 10.1056/NEJMoa1509164

Radtke, F., MacDonald, H. R., and Tacchini-Cottier, F. (2013). Regulation of innate and adaptive immunity by notch. Nat. Rev. Immunol. 13, 427-437. doi: 10.1038/ nri3445

Radtke, F., Wilson, A., Stark, G., Bauer, M., van Meerwijk, J., MacDonald, H. R., et al. (1999). Deficient $\mathrm{T}$ cell fate specification in mice with an induced 
inactivation of Notch1. Immunity 10, 547-558. doi: 10.1016/S1074-7613(00) 80054-80050

Rankin, L. C., Groom, J. R., Chopin, M., Herold, M. J., Walker, J. A., Mielke, L. A., et al. (2013). The transcription factor T-Bet is essential for the development of NKp46+ innate lymphocytes via the notch pathway. Nat. Immunol. 14, 389-395. doi: 10.1038/ni.2545

Rothenberg, E. V., Kueh, H. Y., Yui, M. A., and Zhang, J. A. (2016). Hematopoiesis and T-Cell specification as model developmental system. Immunol. Rev. 271, 72-97. doi: 10.1111/imr.12417

Saito, T., Chiba, S., Ichikawa, M., Kunisato, A., Asai, T., Shimizu, K., et al. (2003). Notch2 is preferentially expressed in mature B cells and indispensable for marginal Zone B lineage development. Immunity 18, 675-685. doi: 10.1016/ S1074-7613(03)00111-110

Schmitt, T. M., and Zúñiga-Pflücker, J. C. (2002). Induction of T cell development from hematopoietic progenitor cells by delta-like-1 in vitro. Immunity 17, 749-756. doi: 10.1016/S1074-7613(02)00474-470

Soto-Feliciano, Y. M., Bartlebaugh, J. M. E., Liu, Y., Sánchez-Rivera, F. J., Bhutkar, A., Weintraub, A. S., et al. (2017). PHF6 regulates phenotypic plasticity through chromatin organization within lineage-specific genes. Genes Dev. 31, 973-989. doi: $10.1101 / \operatorname{gad} .295857 .117$

Taghon, T., Yui, M. A., Pant, R., Diamond, R. A., and Rothenberg, E. V. (2006). Developmental and molecular characterization of emerging $\beta$ - and $\Gamma \delta$-selected Pre-T Cells in the adult mouse thymus. Immunity 24, 53-64. doi: 10.1016/j. immuni.2005.11.012

Taghon, T., Waegemans, E., and Van de Walle, I. (2012). Notch signaling during human T cell development. Curr. Top. Microbiol. Immunol. 360:75-97. doi: 10.1007/82_2012_230

Tian, Y., Xu, J., Feng, S., He, S., Zhao, S., Zhu, L., et al. (2017). The first wave of $\mathrm{T}$ lymphopoiesis in zebrafish arises from aorta endothelium independent of hematopoietic stem cells. J. Exper. Med. 214:3347. doi: 10.1084/JEM.201 70488

Todd, M. A., Ivanochko, D., and Picketts, D. J. (2015). PHF6 degrees of separation: the multifaceted roles of a chromatin adaptor protein. Genes 6, 325-352. doi: 10.3390/genes6020325

Todd, M. A. M., and Picketts, D. J. (2012). PHF6 interacts with the nucleosome remodeling and deacetylation (NuRD) complex. J. Proteome Res. 11, 43264337. doi: 10.1021/pr3004369

Van de Walle, I., De Smet, G., De Smedt, M., Vandekerckhove, B., Leclercq, G., Plum, J., et al. (2009). An early decrease in notch activation is required for human TCR-A $\beta$ lineage differentiation at the expense of TCR- $\Gamma \delta$ T cells. Blood 113, 2988-2998. doi: 10.1182/blood-2008-06-164871

Van de Walle, I., De Smet, G., Gärtner, M., De Smedt, M., Waegemans, E., Vandekerckhove, B., et al. (2011). Jagged2 Acts as a delta-like notch ligand during early hematopoietic cell fate decisions. Blood 117, 4449-4459. doi: 10. 1182/blood-2010-06-290049

Van de Walle, I., Dolens, A. C., Durinck, K., De Mulder, K., Van Loocke, W., Damle, S., et al. (2016). GATA3 induces human T-cell commitment by restraining notch activity and repressing NK-cell fate. Nat. Commun. 7:11171. doi: 10.1038/ ncomms 11171

Van de Walle, I., Waegemans, E., De Medts, J., De Smet, G., De Smedt, M., Snauwaert, S., et al. (2013). Specific notch receptor-ligand interactions control human TCR-A $\beta / \Gamma \delta$ development by inducing differential notch signal strength. J. Exper. Med. 210, 683-697. doi: 10.1084/jem.20121798

Van Vlierberghe, P., Palomero, T., Khiabanian, H., Van der Meulen, J., Castillo, M., Van Roy, N., et al. (2010). PHF6 mutations in T-Cell acute lymphoblastic leukemia. Nat. Genet. 42, 338-342. doi: 10.1038/ng.542
Vicente, C., Schwab, C., Broux, M., Geerdens, E., Degryse, S., Demeyer, S., et al. (2015). Targeted sequencing identifies associations between IL7R-JAK mutations and epigenetic modulators in T-cell acute lymphoblastic leukemia. Haematologica 100, 1301-1310. doi: 10.3324/haematol.2015.130179

Volders, P. J., Helsens, K., Wang, X., Menten, B., Martens, L., Gevaert, K., et al. (2013). LNCipedia: a database for annotated human IncRNA transcript sequences and structures. Nucleic Acids Res. 41, D246-D251. doi: 10.1093/nar/ gks915

Waegemans, E., Van de Walle, I., De Medts, J., De Smedt, M., Kerre, T., Vandekerckhove, B., et al. (2014). Notch3 activation is sufficient but not required for inducing human T-lineage specification. J. Immunol. 193, 59976004. doi: 10.4049/jimmunol.1400764

Wang, J., Leung, J. W., Gong, Z., Feng, L., Shi, X., and Chen, J. (2013). PHF6 regulates cell cycle progression by suppressing ribosomal RNA synthesis. J. Biol. Chem. 288, 3174-3183. doi: 10.1074/jbc.M112.414839

Wang, Q., Qiu, H., Jiang, H., Wu, L., Dong, S., Pan, J., et al. (2011). Mutations of PHF6 are associated with mutations of NOTCH1, JAK1 and rearrangement of SET-NUP214 in T-Cell acute lymphoblastic leukemia. Haematologica 96, 1808-1814. doi: 10.3324/haematol.2011.043083

Wendorff, A. A., Quinn, S. A., Rashkovan, M., Madubata, C. J., AmbesiImpiombato, A., Litzow, M. R., et al. (2019). Phf6 loss enhances HSC selfrenewal driving tumor initiation and leukemia stem cell activity in T-ALL. Cancer Discov. 9, 436-451. doi: 10.1158/2159-8290.CD-18-1005

Weng, A. P., Ferrando, A. A., Lee, W., Morris, J. P. IV, Silverman, L. B., SanchezIrizarry, C., et al. (2004). Activating mutations of NOTCH1 in human T cell acute Lymphoblastic leukemia. Science 306, 269-271. doi: 10.1126/science. 1102160

Wilson, A., MacDonald, H. R., and Radtke, F. (2001). Notch 1-deficient common lymphoid precursors adopt a B Cell fate in the thymus. J. Exper. Med. 194, 1003-1012. doi: 10.1084/jem.194.7.1003

Yashiro-Ohtani, Y., Ohtani, T., and Pear, W. S. (2010). Notch regulation of early thymocyte development. Semin. Immunol. 22, 261-269. doi: 10.1016/j.smim. 2010.04.015

Zhang, C., Mejia, L. A., Huang, J., Valnegri, P., Bennett, E. J., Anckar, J., et al. (2013). The X-linked intellectual disability protein PHF6 associates with the PAF1 complex and regulates neuronal migration in the mammalian brain. Neuron 78, 986-993. doi: 10.1016/j.neuron.2013.04.021

Zhang, Y., and Wiest, D. L. (2016). Using the zebrafish model to study T cell development. Methods Mol. Biol. 1323, 273-292. doi: 10.1007/978-1-49392809-5_22

Conflict of Interest: The authors declare that the research was conducted in the absence of any commercial or financial relationships that could be construed as a potential conflict of interest.

The handling editor declared a shared affiliation with several of the authors, FM and DL, at the time of review.

Copyright (C) 2020 Loontiens, Dolens, Strubbe, Van de Walle, Moore, Depestel, Vanhauwaert, Matthijssens, Langenau, Speleman, Van Vlierberghe, Durinck and Taghon. This is an open-access article distributed under the terms of the Creative Commons Attribution License (CC BY). The use, distribution or reproduction in other forums is permitted, provided the original author(s) and the copyright owner(s) are credited and that the original publication in this journal is cited, in accordance with accepted academic practice. No use, distribution or reproduction is permitted which does not comply with these terms. 